\title{
A Study of the Functional Mechanism of Petrochemical Engineering Construction Project Management
}

\begin{abstract}
This paper, proceeding from the project construction process, the management mode and the implementation way, makes an in-depth study of the environmental characteristics and the managerial elements of petrochemical engineering construction project, revealing the inherent laws, establishing a theoretical model, and proposing a theory of the mechanisms of construction project management; and presents profound revelations found for construction project management in petrochemical engineering in seven aspects, which can play a guiding role in improving the managerial performance of petrochemical construction project. The theory established proposes that: The construction project management in petrochemical engineering is a complex systematic process, formed of 5 phases and 55 sub-processes of management, and exposed to many factors of influence; the environmental characteristics and managerial elements exercise positive impacts on managerial performance, but different factors have different impacts and act in different ways on managerial performance; the managerial elements of petrochemical engineering construction project are tiered, transferable, systematic and quantifiable, and the role of managerial elements in the managerial performance can be systematically integrated, quantitatively explained and transferred in a multi-level way.
\end{abstract}

Keywords: petrochemical engineering, construction project, project management, functional mechanism

Petrochemical engineering construction project is a highly intensive project integrating resources, funds and technology, featured by complex technology, diversified specialties, wide fields, high degree of integration, large investment, long period of construction and high requirement of quality. The level of project management is the key to the success of engineering construction project. To this end, we made a

Manuscript received April 2, 2014; accepted June 4, 2014

Ji-ming Wang (凶)

China Petroleum and Chemical Industry Federation, Beijing 100732, China

Email: liujun@sinopec.com systematic research on the construction process, management mode, implementation way, functional mechanism of project management and project performance evaluation system. Here, we briefly report the study on functional mechanism of project management as follows.

\section{Construction process and management mode of petrochemical engineering construc- tion project}

Petrochemical engineering construction is complex system engineering and must follow the necessary procedures. According to the procedures of engineering construction, the petrochemical engineering construction project is divided into 5 phases and 55 sub-processes.

1.1 Main construction phases and processes of petrochemical engineering construction project

Based on the schedule of project implementation, the construction process of petrochemical engineering construction project is usually divided into 5 phases: (1) preparatory work; (2) project definition; (3) project implementation; (4) commissioning and final acceptance; (5) post-construction evaluation.

(1) Preparatory work. This phase targets at project approval, determines a project that conforms to the long-term planning of national economic and social development and the planning of industrial, regional and corporate development through market research, investment opportunity research, feasibility study, and special approval.

(2) Project definition. The phase is the preparatory phase of project implementation. Based on the approved feasible report, it determines project management modes and organizations, selects technical route and basic engineering design, handles relevant procedures related with project commencement, carries out construction funds, determines contractors and supervision units, completes "four supplies and one leveling" (supply of water, roads, electricity, telecommunications and leveled ground), and makes preparation for the full 
implementation of the project.

(3) Project implementation. The main task of this phase is to develop the overall coordination control plan; carry out detailed engineering design, engineering equipment and materials procurement; conduct civil works and installation engineering; supervise project and quality control; complete the construction according to the design requirements and make preparation for the production.

(4) Commissioning and final acceptance. The main task of this phase is to transact trial production-related filing procedures from governmental departments; carry out commissioning, assessment and delivery for acceptance; meet all standards in final accounts, audit and final acceptance.

(5) Post-construction evaluation. This phase is to make a systematic, objective and comprehensive analysis on the execution, effectiveness, impact of the completed project; sum up experience and lessons; make recommendations for decision-making in future construction projects and improving investment decision-making and management level in the coming years.

The above 5 phases, based on different processes, can be further divided into the following 55 sub-processes.

(1) Thirteen sub-processes of preparatory work: determination of pre-phase project management organization; regional/industrial planning; research of investment opportunities; site selection; market study (raw materials, products); program study/pre-feasibility study; funds financing; feasibility study and review; pre-audit of site selection and planning land; assessment and approval of environmental impact assessment (EIA) report; evaluation and approval/ registration of project application report; pre-evaluation, review and approval of safety; evaluation, review and approval of occupational hazard.

(2) Sixteen sub-processes of project definition: determination of management mode and implementation way of engineering construction and project management organizations; official permission of land planning; selection of technology; design and review of process package; preparation of uniform provisions on project, and determination of the design principles, technical standard and design basis; preparation of overall design, review and approval; geological survey; basic engineering design, review and approval; determination of procurement strategy and procurement planning; long-period equipment ordering; constructionability study; transaction of land acquisition procedures and license of construction project planning; "four supplies and one leveling"; review of building construction license and project commencement report; implementation of construction funds; determination of supervision contractor and project contractor.

(3) Twelve sub-processes of project implementation: determination of production management mode and production preparation, organization of trial production, production preparation and personnel training; compilation and review of Overall Planning Control Plan; project supervision; quality supervision; detailed engineering design; engineering procurement; foundation treatment; civil works; installation project; production preparation; single machine commissioning, air tight purging; three examinations and four sets (examine the design items, engineering quality and hidden trouble, as well as the amount of construction in progress; set tasks, personnel, time and measures) and provisional acceptance.

(4) Twelve sub-processes of commissioning and final acceptance: linkage test; pilot production program security filing; special equipment registration; fire inspection and pre-acceptance of environmental protection; commissioning; occupational health, labour safety, special acceptance of environmental protection; production assessment and calibration; delivery and acceptance; completion settlement; project audit; project file acceptance; completion and acceptance.

(5) Two sub-processes of post-construction evaluation: self-evaluation and independent evaluation. The main contents of post-construction evaluation: evaluation of project objectives, project implementation process, project benefit, project impact, and project sustainability.

The above 5 phases and 55 sub-processes have complex interfacial relationship and have much connection with the external environment. To do a good job in each sub-process and properly handle the relationship between the interface and the connection is an important task of the project manager, and also the key for the success of project.

\subsection{Management mode of petrochemical engineering project}

The management mode of engineering construction project is an important foundation for the effective management of quality, HSE (health, safety, environment), schedule, cost and contract of engineering construction project. In practice, the management mode of engineering construction project has a variety of types; each mode has its advantages and corresponding limitations, applicable to different types of projects. In recent years, the management modes commonly used by the owners of petrochemical engineering construction projects have the following three types: self-operating management of owners, project management contractor and integrated project management team.

\subsubsection{Self-operating management of owners}

As for this mode, the owners (or construction units) establish construction management agency and work with the designing parties, equipment and material suppliers and construction parties to sign contracts and organize the appropriate project management team on their own to manage the implementation process of the project. This mode is one of the China's major domestic construction project management modes.

\subsubsection{Project management contractor (PMC)}

A project company with considerable strength is commis- 
sioned as a PMC to conduct a comprehensive management on project and timely report to the owners, the owners need only to send a few of personnel to supervise and review PMC work. PMC's mission is shown as follows.

(1) Represent the owners to manage the pre-phased project, including optimize project construction program; propose a unified criterion and regulation; prepare basic engineering design (preliminary design) files and determine all technical solutions and major professional design programs; conduct investment estimates; prepare design-procurement-construction (EPC) tender invitation documents and complete tender invitation and tender evaluation; complete inquiry and pre-procurement of longperiod equipment and bulk materials; provide financing options upon request and assist owners in financing.

(2) Represent the owners to manage and supervise the contractors' detailed engineering, procurement and construction.

(3) Work with the owners for manufacturing, commissioning, device examination and acceptance.

\subsubsection{Integrated project management team (IPMT)}

IPMT is a project management team composed of owners and professional project management companies, is a project management mode that Sinopec Group independently innovates and develops based on its years' construction practice. IPMT represents the owners to conduct a comprehensive management for the overall project planning, project definition, project tendering, project construction, commissioning, assessment and acceptance, responsible for selecting the pre-project advisers, EPC contractors and supervision contractors, and coordinating their works.

Compared with the previous two modes, IPMT has the following four characteristics.

(1) Owners work with professional management companies to exert their advantages. The project managers of own- ers and experts of professional project management consulting companies organize a joint project management team, which can not only show professional personnel's project management experience and management technology, but also play the leading role of the owners in carrying out project.

(2) Combine petrochemical engineering construction management experience and advanced technology. The managers of the owners have rich experience in petrochemical engineering construction, while the project management consulting company has advanced and scientific project management techniques and methods, thus joint efforts made by both sides will improve construction management.

(3) Owners' strong capability of control is in favor of playing a leading role. In IPMT organization, the consulting company mainly provides technology, methods and recommendations, and the owners make important decisions.

(4) Applicable to the management of large-scale petrochemical engineering construction project with strong ability of management.

Features and applicable scope of the above three management modes see Table 1.

1.3 Implementation way of petrochemical engineering construction project

Implementation of engineering construction project involves engineering design, equipment and material procurement and project construction. The implementation ways are generally divided into EPC, lump sum turn key (LSTK), "design-purchase+construction" $(\mathrm{EP}+\mathrm{C})$, "design+ procurement-construction" (E+PC), "design+purchase+construction" $(\mathrm{E}+\mathrm{P}+\mathrm{C})$, etc.

Due to different project characteristics and owner's characteristics, one or more of the above implementation ways of engineering construction project will be used.

Table 1 Features and Applicable Scope of the Three Management Modes

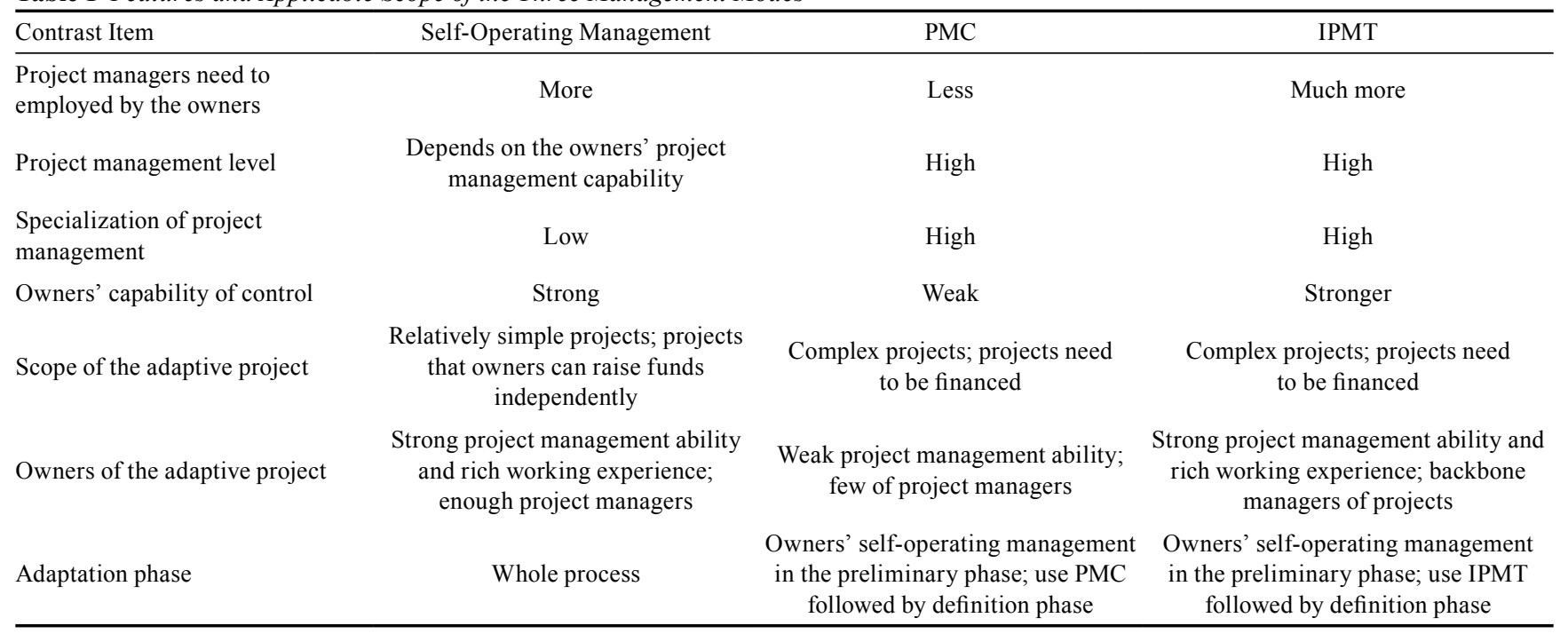


1.4 Combination and selection of management mode and implementation way

There are a variety of management modes and implementation ways in the process of project implementation. As for the projects with less complexity and small scale, and its owner has strong project management capability, the selfoperating management and $\mathrm{E}+\mathrm{P}+\mathrm{C}$ or $\mathrm{EPC}$ are usually used; as for the projects with more complexity, and its owner is lack of project management resources and weak in project management capability, $\mathrm{PMC}+\mathrm{EPC}$ (or $\mathrm{E}+\mathrm{P}+\mathrm{C}$ ) is usually used; as for complex and large-scale projects, the owners have more management resources and strong management capability, IPMT+EPC is usually used.

Taking a full consideration of various factors, we believe that the selection of appropriate project management modes and implementation ways should base on the following principles.

(1) If the personnel of the owners and staff employed by the owners are able to organize a project management team, self-operating management mode should be selected. In this case: (1) if owners' professional managers have strong ability and are competent for the interface management of engineering design, procurement and construction, the combination of "self-operating management $+\mathrm{E}+\mathrm{P}+\mathrm{C}$ " should be selected; (2) if owners' professional managers are incompetent for the interface management of engineering design, procurement and construction, the combination of "self-operating management + EPC" should be selected. During the period of execution, EPC can have many variants.

(2) If the personnel of the owners and staff employed by the owners are unable to organize a project management team, PMC should be selected. In this case: (1) if the subprojects have clear and simple interfaces, the combination of "PMC+EPC" should be selected, such as the petrochemical process plant; (2) if the subprojects have complex and more interfaces, the combination of "PMC+E+P+C" should be selected, such as some utilities and auxiliary facilities.

(3) If the personnel of the owners and staff employed by the owners are able to organize a project management team, the absent specific project management professionals can be provided by project management company, and IPMT should be selected. In this case: (1) if IPMT professional managers are competent for the interface management of engineering design, procurement and construction, the combination of "IPMT $+\mathrm{E}+\mathrm{P}+\mathrm{C}$ " should be selected; (2) if IPMT professional managers are incompetent for the interface management of engineering design, procurement and construction, a combination of "IPMT+EPC" should be selected. During the period of execution, EPC can have many variants.

Any combination must make sure the division of responsibility and interface of owners, project management companies and contractors in project contract and project planning, and ensure a reasonable framework of project organization, a clear division of responsibilities, clear interface management and streamlined workflow.

\section{Study on functional mechanism of petro- chemical engineering construction project management}

The study targets at scientifically exploring the core management elements that impact on the success of projects and studying the intrinsic ties between the core management element and project objectives, and ties among different management elements. This is the connotation of functional mechanism of engineering construction project management and also the main task for studying the functional mechanism of project management.

2.1 Study on environmental characteristics and management elements of petrochemical engineering construction project

The study is to propose a concept variable for building a theoretical model of functional mechanism of project management.

\subsubsection{Environmental characteristics}

Environmental characteristics are the objective basis of project management, including project characteristics, owner's characteristics and monitoring party's characteristics, and also the main factor to determine the project management mode and implementation way.

Project characteristic is the property to measure project feature, including the scope, scale, construction goals of the project (including quality, safety, environment protection, efficiency and progress), advanced technology, internal and external environment, as well as the complexity of construction project, etc. Project characteristics do exist objectively. Once the project is determined, the project characteristics will be determined. Project characteristics are the important foundation to determine management mode, implementation way and management approach.

Owner's characteristics reflect the property of owner's feature, including institutional mechanism of owner's enterprise, management skills, management experience, technological level, and financial resource of project management team. Owner's characteristics will have a significant impact on management mode, organization, planning and administration of the project, and determine the owner's controlling force on the project to some extent.

Monitoring party's characteristics reflect the property of management capability, management level and service level of monitoring party, and can restrain the project. Project monitoring party refers to the third party that monitors the implementation of the project, including governmental administrative departments in charge of construction, environmental protection, bidding and tendering, quality and technical supervision, safety supervision, customs, engineering quality supervision station, etc. 


\subsubsection{Project management elements}

Project management process involves a lot of management elements. We got 10 major management elements: project organization, project planning, communication and coordination, contract management, risk management, schedule management, cost management, quality management, HSE management, technology management.

\subsubsection{Project organization}

Project organization is to, based on project characteristics and owner's characteristics, determine the management mode and organizations, confirm division of responsibilities and interface relationship among departments and positions, and form an effective project team.

Project organization is mainly affected by project characteristics, owner's characteristics, monitoring party's characteristics and project planning. The large-scale projects with complex technology, difficult management and complex interface relationship need more competent personnel and powerful organizations.

Project organization has an important impact on the success of the project. A reasonable project organization can improve the efficiency of project team and the realization of project objectives, help to optimize the allocation of resources, facilitate the coordination of internal and external relations of the project.

\subsubsection{Project planning}

Project planning is carried out in the initial phase of the project till the end of construction process; the direct result of project planning is to form project plan. In the process of project implementation, based on the changing circumstances, we should timely adjust and improve the project planning to lay a good foundation for the smooth implementation of project management.

Project planning generally includes: develop project execution strategy; determine project objectives including quality, HSE, cost, schedule, etc.; determine the scope and breakdown structure of project, project management mode, institutional framework and the division of responsibilities; make clear management procedures and control points of quality, HSE, cost and schedule; develop key implementation points of preliminary work, design, procurement, construction and commissioning; develop resource allocation plan; determine project communication procedures; analyze project risks and develop countermeasures.

A great deal of management practice in engineering construction projects has proved that good project planning is fundamental for the success of the project.

\subsubsection{Communication and coordination}

Communication and coordination means to timely and appropriately generate, collect, analyze, deliver, save and han- dle the project information; coordinate internal and external relations; exchange information; eliminate misunderstandings and barriers; resolve contradictions, and so on.

\subsubsection{Contract management}

Contract management means to carry out management activities to get products and services from outside the project. Its main contents include: develop an effective contracting and procurement planning; conduct pre-qualification, tendering, bid evaluation and scaling, contract signing according to relevant laws, regulations and administrative procedures; monitor the implementation of contract in the process of executing project; handle the matters such as contract changes, breach of contract and claims, disputes and contract termination, procurement of equipment and materials as well as tendering of patent suppliers and contractors.

\subsubsection{Risk management}

Risk management means to identify, analyze, respond and monitor the project risks. As the project progresses, the project risks are constantly evolving, we need to timely identify, and analyze and take measures to deal with risks and reduce the risk to a minimum.

\subsubsection{Schedule management}

Schedule management means to develop schedule control procedures and progress schedule, detect actual progress and analyze deviation, take corrective measures to ensure that each node and overall mission can be completed on schedule. Schedule management includes the workout and control of project schedule.

\subsubsection{Cost management}

Cost management means to estimate, budget and control the project cost.

\subsubsection{Quality management}

Quality management means to create project quality management system based on quality management standards, carry out management and control activities to achieve quality objectives. Project quality management includes quality planning, quality assurance, quality control and quality improvement, etc.

\subsubsection{HSE management}

HSE management means to analyze, forecast, evaluate, respond, track and monitor the occupational health, safety and environmental factors in the process of project construction. HSE management should adhere to the "prevention first" principle, identify the source of hazard and analyze the risks to determine the hazards and consequences of accidents that 
may occur, map out management objectives and management plans, prevent or reduce personal injury, property loss and environmental impact caused by accidents.

\subsubsection{Technology management}

Technology management is the generic terms of scientific management for all technical activities in the process of implementing the entire project, including process technology management, engineering technology management, safety and environmental protection technology management, technological innovation, technology files management and technical training. Project management is an important work throughout technology management activities.

2.2 Set up theoretical model of functional mechanism of petrochemical engineering construction project management

We adopted an empirical method based on questionnaire and statistical analysis and conducted a questionnaire on 500 experts of Sinopec with extensive practical experience, involving more than 1,000 projects, more than 0.3 million data. On this basis, we conducted an in-depth research on the relationship among environmental characteristics, management elements and project performance of petrochemical engineering construction project, and set up a theoretical model of functional mechanism of petrochemical engineering construction project management (see Figure 1).

Since the variables involved in the study on functional mechanism of engineering construction project management are featured by difficult observation and measurement, and multicollinearity, as well as difficult experimental research, we decided to adopt structural equation modeling (SEM) method to overcome these difficulties so as to set up a theoretical model.

SEM is adopted as the following steps (estimation and evaluation can be finished through the commonly used software-AMOS and LISREL).

Figure 2 shows the acceptable model repeatedly discussed, verified and revised by exports on the basis of a plenty of questionnaire.

The SEM indicated by path diagram shows the relationship between the 3 variables of environmental characteristics and 10 variables of management elements, and the effect of these variables on project management performance variables. Effects between variables have indirect and direct effects. The effect of adjacent variables is direct, and the effect passed by other variables is indirect. The acting relationship and extent of the variables are indicated by path coefficients in Table 2.

The data listed in Table 2 is the actuating data among standardized variables. The first line variables are actuating variables, and the first column variables are actuated variables. The data listed in the table have overall, direct and indirect actuations, and entire actuation is the sum of direct and indirect actuations. The path coefficient in the model of path diagram is overall actuating data.

Mechanistic model shown in Figure 1 reflects five tiers: environmental characteristics, organizational planning, comprehensive management, specific management and management performance.

(1) The three variables - project characteristics, owner's characteristics and monitoring party's characteristics of environmental characteristics have a direct effect on the two variables - project organization and project planning of organizational planning, then have an indirect effect on the subsequent variables through the two variables, finally, have an indirect effect on management performance variable.

(2) The two variables - project organization and project planning of organizational planning firstly have a direct effect on the three variables - coordination and communication, contract management and risk management of integrated management, then have an indirect effect on special project management variable and performance management variable through the three variables.

(3) The three variables-coordination and communication, contract management and risk management of integrated management act directly on the five special management variables - schedule management, cost management, quality management, HSE management, technology management, then indirectly act on project management performance variable.

(4) The five variables - schedule management, cost management, quality management, HSE management and tech-

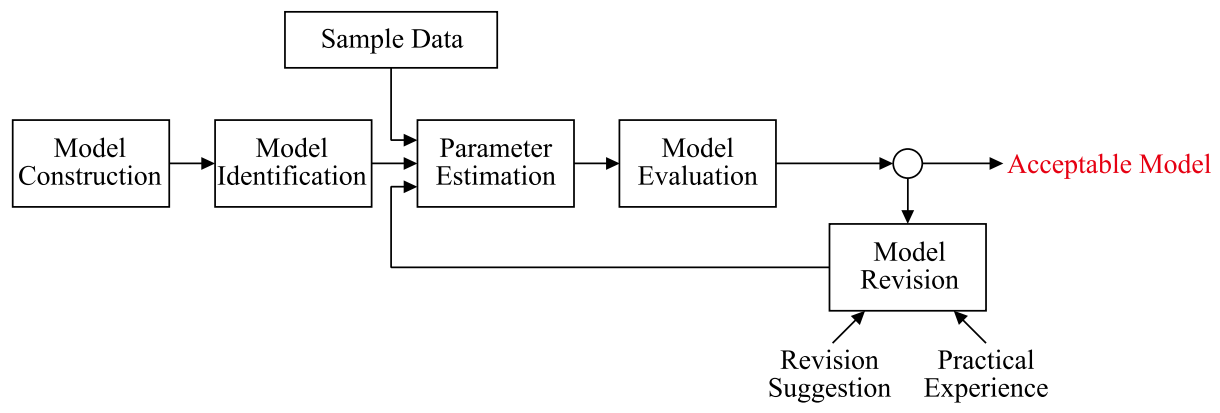

Figure 1. The steps of the SEM. 


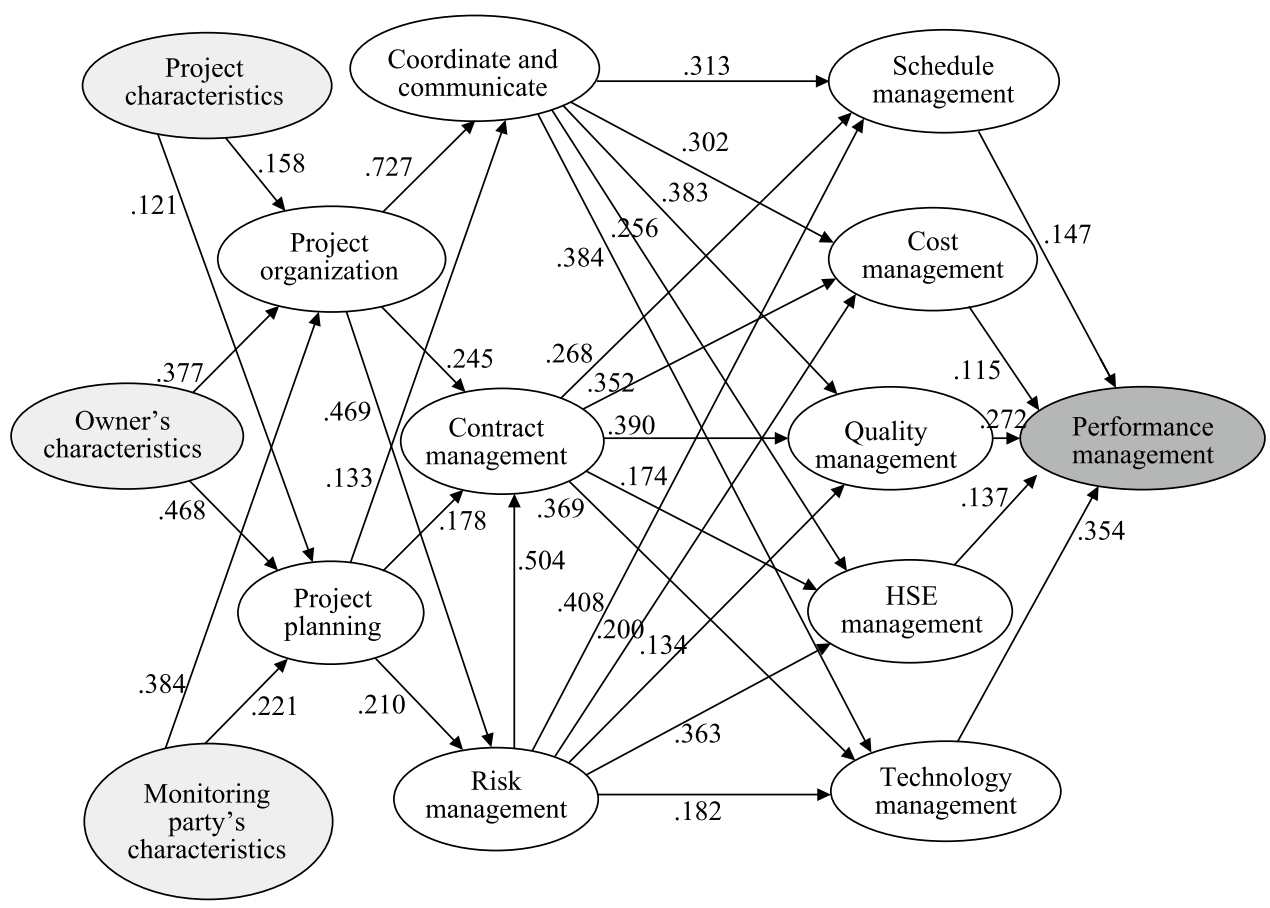

Figure 2. Theoretical model of functional mechanism of petrochemical engineering construction project management.

Table 2 The Acting Relationship and Extent of Standardized Variables

\begin{tabular}{|c|c|c|c|c|c|c|}
\hline Actuation $\measuredangle$ Direction & $\begin{array}{c}\text { Project } \\
\text { Characteristics }\end{array}$ & $\begin{array}{c}\text { Owner's } \\
\text { Characteristics }\end{array}$ & $\begin{array}{l}\text { Monitoring Party's } \\
\text { Characteristics }\end{array}$ & $\begin{array}{c}\text { Project } \\
\text { Organization }\end{array}$ & Project Planning & $\begin{array}{c}\text { Coordination and } \\
\text { Communication }\end{array}$ \\
\hline \multicolumn{7}{|l|}{ Entire Actuation } \\
\hline Project Organization & 0.158 & 0.377 & 0.384 & & & \\
\hline Project Planning & 0.121 & 0.468 & 0.221 & & & \\
\hline $\begin{array}{l}\text { Coordination and } \\
\text { Communication }\end{array}$ & 0.131 & 0.336 & 0.308 & 0.727 & 0.133 & \\
\hline Contract Management & 0.111 & 0.314 & 0.248 & 0.482 & 0.284 & \\
\hline Risk Management & 0.100 & 0.275 & 0.226 & 0.469 & 0.210 & \\
\hline Schedule Management & 0.111 & 0.302 & 0.256 & 0.548 & 0.203 & 0.313 \\
\hline Cost Management & 0.098 & 0.267 & 0.225 & 0.482 & 0.182 & 0.302 \\
\hline Quality Management & 0.107 & 0.288 & 0.245 & 0.529 & 0.190 & 0.383 \\
\hline HSE Management & 0.089 & 0.241 & 0.204 & 0.440 & 0.160 & 0.256 \\
\hline Technology Management & 0.109 & 0.295 & 0.251 & 0.542 & 0.194 & 0.384 \\
\hline Performance Management & 0.108 & 0.291 & 0.247 & 0.533 & 0.193 & 0.357 \\
\hline \multicolumn{7}{|l|}{ Direct Actuation } \\
\hline Project Organization & 0.158 & 0.377 & 0.384 & & & \\
\hline Project Planning & 0.121 & 0.468 & 0.221 & & & \\
\hline $\begin{array}{l}\text { Coordination and } \\
\text { Communication }\end{array}$ & & & & 0.727 & 0.133 & \\
\hline Contract Management & & & & 0.245 & 0.178 & \\
\hline Risk Management & & & & 0.469 & 0.210 & \\
\hline Schedule Management & & & & & & 0.313 \\
\hline Cost Management & & & & & & 0.302 \\
\hline Quality Management & & & & & & 0.383 \\
\hline HSE Management & & & & & & 0.256 \\
\hline Technology Management & & & & & & 0.384 \\
\hline Performance Management & & & & & & \\
\hline
\end{tabular}




\begin{tabular}{|c|c|c|c|c|c|c|}
\hline \multicolumn{7}{|l|}{ Indirect Actuation } \\
\hline \multicolumn{7}{|l|}{ Project Planning } \\
\hline $\begin{array}{l}\text { Coordination and } \\
\text { Communication }\end{array}$ & 0.131 & 0.336 & 0.308 & & & \\
\hline Risk Management & 0.100 & 0.275 & 0.226 & & & \\
\hline Schedule Management & 0.111 & 0.302 & 0.256 & 0.548 & 0.203 & \\
\hline Cost Management & 0.098 & 0.267 & 0.225 & 0.482 & 0.182 & \\
\hline Quality Management & 0.107 & 0.288 & 0.245 & 0.529 & 0.190 & \\
\hline Actuation $\measuredangle$ Direction & $\begin{array}{c}\text { Contract } \\
\text { Management }\end{array}$ & $\begin{array}{c}\text { Risk } \\
\text { Management }\end{array}$ & $\begin{array}{c}\text { Schedule } \\
\text { Management }\end{array}$ & $\begin{array}{r}\text { Que } \\
\text { Manas }\end{array}$ & $\begin{array}{c}\text { HSE } \\
\text { Management }\end{array}$ & $\begin{array}{c}\text { Technology } \\
\text { Management }\end{array}$ \\
\hline
\end{tabular}

Entire Actuation

Project Organization

Project Planning

Coordination and

Communication

Contract Management

0.504

Risk Management

Schedule Management

$0.268 \quad 0.543$

Cost Management

$0.352 \quad 0.377$

Quality Management

0.390

0.330

HSE Management

0.174

0.451

Technology Management

0.369

0.368

Performance Management

0.341

0.406

0.147

0.115

0.272

0.137

0.354

Direct Actuation

Project Organization

Project Planning

Coordination and

Communication

Contract Management

0.504

Risk Management

Schedule Management

$\begin{array}{ll}0.268 & 0.408 \\ 0.352 & 0.200 \\ 0.390 & 0.134 \\ 0.174 & 0.363 \\ 0.369 & 0.182\end{array}$

Cost Management

200

Quality Management

HSE Management

0.182

Technology Management

0.147

0.115

0.272

0.137

0.354

Indirect Actuation

Project Organization

Project Planning

Coordination and

Communication

Contract Management

Risk Management 


\begin{tabular}{|c|c|c|c|c|c|c|c|}
\hline Schedule Management & & 0.135 & & & & & \\
\hline Quality Management & & 0.196 & & & & & \\
\hline HSE Management & & 0.088 & & & & & \\
\hline Performance Management & 0.341 & 0.406 & & & & & \\
\hline
\end{tabular}

nology management of special management have a direct effect on project management performance.

(5) Project management performance, as the ultimate dependent variable, is affected by 13 variables including environmental characteristics, organizational planning, integrated management and special management, among which, 8 variables indirectly act on, 5 variables directly act on project management performance. Its actuating relationship sees the formula below:

Management performance $=$ Direct part $(0.147$ schedule management +0.115 cost management +0.272 quality management +0.137 HSE management +0.354 technology management)+Indirect part 1 ( 0.357 coordination and communication +0.341 contract management +0.406 risk management)+Indirect part 2 (0.533 project organization +0.193 project planning)+Indirect part 3 (0.108 project characteristics +0.291 owner's characteristics +0.247 monitoring party's characteristics)

Through the formula, we can see as follows.

(1) 13 actuating variables' average influence on project management performance is 0.27 .

(2) Direct influence of 5 variables of special management tier is less than the indirect influence of other 8 variables, and the ratio is approximately $3: 7$. The direct actuating extent of the 5 special management variables averages 0.2 ; the indirect actuating extent of the other 8 variables averages 0.3 .

(3) Among the 13 actuating variables, the influence of project organization tops the rank $(0.533)$, followed by risk management, communication and coordination, contract management and technology management variables $(>0.34)$; the influence of owner's characteristics, monitoring party's characteristics, quality management and project planning is in the middle (0.193-0.291); the influence of project characteristics, schedule management, cost management and HSE management is on the bottom $(<0.15)$.

Management performance of petrochemical engineering construction projects is composed of 6 measuring variables, namely project management performance is measured by the 6 measuring variables. See the formula below:

Management performance $=0.694$ quality +0.603 building cost +0.595 construction period +0.686 HSE +0.780 technology +0.645 efficiency

The important extent of measuring variables of these 6 project management performance is basically similar.
Relatively speaking, the effect on performance is ordered as such: technology, quality, HSE, efficiency, building cost and construction period.

2.3 Theory of functional mechanism of petrochemical engineering construction project management

Through research, we propose the basic connotation of theory of functional mechanism of petrochemical engineering construction project management.

(1) Petrochemical engineering construction project management is a complex systematic engineering, including 5 phases and 55 sub-processes, affected by many factors. These factors include environmental characteristic and management element. Project environmental characteristic is the basic condition of project management, a major factor to determine management mode and implementation way. The environmental characteristic of project management is mainly composed of project characteristic, owner's characteristic and monitoring party's characteristic. Project management element is the management factor that affects management performance, including 10 management factors such as project organization, project planning, communication and coordination, contract management, risk management, schedule management, cost management, quality management, HSE management and technology management.

(2) Project environmental characteristic and management element play a positive role in performance management, but the impact of various factors on management performance is different, directly or indirectly. They pass on and act on project management performance.

(3) The functional rule of petrochemical engineering construction project management factors is tiered, transmissible, systematic and quantifiable, the effect of management factors on management performance is a multi-level transmitted, systematically integrated and quantitatively explained.

The factors are divided into 5 different tiers. The first tier is environmental characteristic, which plays a constraint role in the project; the second tier is project organization planning, which is an important pre-project management element, having an overall effect; the third tier is integrated management, which plays a comprehensive role in linking the preceding and the following; the fourth tier is special management, which plays a role of special management; 
the fifth tier is project management performance. The first four tiers of factors perform their own functions and transmit with the path of hyperbolic tree successively and are systematically integrated, jointly affecting management performance.

The mechanism model of petrochemical engineering construction project management can quantitatively explain the relationship between two actuating factors, factors and tiers, and tiers and tiers.

The actuating path and degree of the influence factors of petrochemical engineering construction project can be represented in Figure 3. The more left the factors locate, the longer the transmitted path is. The more upper part the factors locate, the greater degree of acting on management performance of petrochemical engineering construction project is.

\subsection{Revelations for petrochemical engineering construction} project management practice

The theory of functional mechanism of petrochemical engineering construction project management is applied in project management practice. The profound revelation can be obtained as follows.

(1) Petrochemical engineering construction project management should adhere to the principle of "global grasp, systematic optimization". Petrochemical engineering construction project management is a systematic engineering, the work result and management level of some phase or sub- process can directly impact on the next phase or subprocess, even the overall situation. Thus, "global grasp, systematic optimization" should be implemented in the process of project management. We should grasp the overall situation starting from system optimization, and do a good job of management in the various phases and sub-processes to improve management efficiency and management level.

(2) Each factor should be given full and adequate consideration. The 13 factors have their own functions at different tiers. The level of project management performance depends on the integration of these factors. Thus, we should give full and adequate consideration to each factor and make a comprehensive understanding of the interaction among the factors. The higher the tier is, the deeper and wider the influence is, such as risk management, communication and coordination, and contract management. Accordingly, we should pay more attention to them.

(3) Project organization and project planning should be carried out in the pre-phase project. Project organization is the most important factor of all key factors, having the biggest and overall influence on the 8 subsequent factors and project management performance. Therefore, in the early stage of the project, we should firstly choose scientific and suitable project organization mode, design rational and effective project organization structure, organize the powerful leadership, rationally optimize the allocation of project resources; besides that, do a good job of project planning in a scientific and forward-looking way and timely develop a

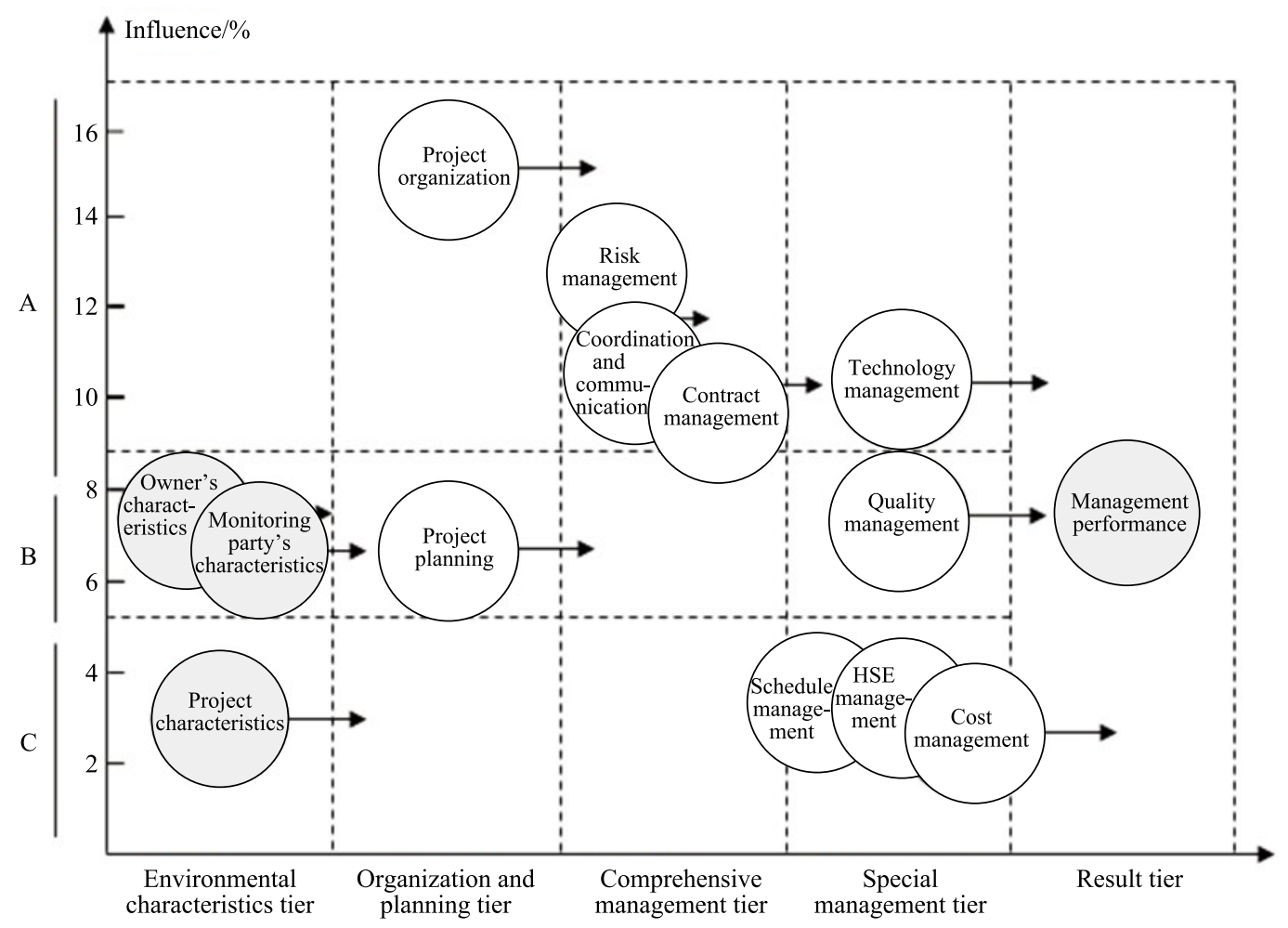

Figure 3. Integrated transfer influence of petrochemical engineering construction project management. 
reasonable implementation plan.

(4) Play a leading role of owner and enhance the ability of owner. The owner is the main body of project, the owner's management and technical capabilities will fundamentally improve the level of project planning and project management performance. Therefore, the owner should act positively to strengthen its ability and improve the level of project planning.

(5) Follow the monitoring procedure and requirement, and improve the level of project management. Monitoring party's characteristics such as monitoring measures and efforts have a significant impact on project organization planning, and the subsequent factors and project management performance. We should strictly follow the monitoring procedures and requirements throughout the process of project management to improve project management.

(6) Integrated management should adequately present its own side according to the specific circumstances. Commu- nication and coordination and contract management have a greater impact on the cost management, quality management and technology, so does the risk management on the project progress and HSE management. Therefore, we should focus on the specific circumstances of special management to strengthen the exchange of information, build good relations among the related parties, make standards and specifications match the contract, and strengthen risk identification, reasonable response and effective control.

(7) Make efforts in technology management and quality management. Complex, interdisciplinary and high quality requirement of petrochemical engineering technology underscore the importance of technology management and quality management for petrochemical engineering construction project management. Therefore, we should give overall consideration to quality management and technology management in carrying out the special management. 